\title{
Femtogram per Milliliter per Milligram per Meter Squared per Day
}

National Cancer Institute

\section{Source}

National Cancer Institute. Femtogram per Milliliter per Milligram per Meter Squared per

Day. NCl Thesaurus. Code C119341.

A unit of concentration equal to femtogram per milliliter, divided by milligrams per meter squared per day. 